\title{
Facial fat grafting with a prototype injection control device
}

\author{
Hugh E Hetherington' \\ Jon E Block ${ }^{2}$ \\ 'Bozeman Deaconess Health Group, \\ Bozeman, MT, USA; ${ }^{2}$ The Jon Block \\ Group, San Francisco, CA, USA
}

Correspondence: Jon E Block

The Jon Block Group, 2210 Jackson

Street, Suite 40I, San Francisco,

CA 94115 , USA

Tel +l 4I5 7757947

Fax +I 4159280765

Email jonblock@jonblockgroup.com
This article was published in the following Dove Press journal:

Clinical, Cosmetic and Investigational Dermatology

12 September 2013

Number of times this article has been viewed

Objective: To evaluate the initial clinical performance of a prototype injection control device (ICD) to facilitate fat grafting by injection.

Methods: An ICD, which mechanically couples the act of withdrawing the cannula with the act of depressing the plunger, was fabricated for the purpose of facial fat grafting. The action of the device results in deposition of consistent threads of fat having a volume of approximately $33 \mathrm{uL}$ per $\mathrm{cm}$ that the cannula is withdrawn, which is slightly less than the internal volume of a 12-gauge cannula. A total of 26 patients underwent 30 procedures, and the results were subjectively evaluated using pre- and postoperative photographs, with a minimum follow-up of 4 months.

Results: The desired degree of correction was more consistent, recovery was faster, and procedural efficiency was improved when performing the procedure with the ICD compared to historical use of the manual method of injection. Minor irregularities were the only complications encountered.

Conclusion: The ICD optimally distributes fat as a uniform thread along the withdrawal tract of the cannula, thereby eliminating clumping and minimizing tissue trauma, resulting in reduced recovery time as well as more consistent and predictable clinical results. Since the ICD automates the injection process, it provides a notable and easily attainable efficiency in procedural time and minimal learning curve for the user.

Keywords: dermal fillers, liposuction, facial rejuvenation, threading

\section{Introduction}

Facial fat grafting was first reported in 1893 when German physician Franz Neuber grafted upper arm fat to a patient's cheek. ${ }^{1}$ The advent of liposuction popularized the concept of fat grafting by injection. ${ }^{2-5}$ Autologous fat graft survival has been reported to range from $20 \%-90 \%$; however, most of these results are based on subjective assessment. ${ }^{6-9}$ There are few objective studies of the volume retention after autologous fat grafting. Hörl et al used MRI to demonstrate 51\% volume retention at 3 months and $45 \%$ volume retention at 6, 9, and 12 months. ${ }^{10}$ Ultrasonography has been used to assess results at up to one-year postop. ${ }^{11}$ Thanik et al demonstrated $82 \%$ volume retention at 8 weeks in a murine model. ${ }^{12}$ A report by Meier et al objectively evaluated volume retention in a series of 33 patients who underwent facial fat grafting to the mid-face with follow-up of at least one year. ${ }^{13}$ The Canfield Scientific Vectra camera and software (Canfield Imaging Systems, Fairfield, NJ, USA) were used to perform three-dimensional imaging with quantitative volume measurements to evaluate the amount of postoperative volume change. Average volume retention was approximately 
$32 \%{ }^{13}$ However, there was marked variability in these results, with a standard deviation of approximately $20 \%$.

Fat atrophy is a significant, if not the primary, factor in facial aging. It is, however, challenging to obtain consistent results using fat as a filler material to correct facial volume loss. When successful, the results can be quite gratifying. In many ways, fat is the ideal subcutaneous filler, because it is living autologous tissue and can be removed if overcorrection occurs. However, fat cells are fragile, and the augmentation may be temporary or unpredictable if a significant proportion of the fat cells die. ${ }^{14}$

To maximize survival, the fat cells must be evenly distributed through the recipient tissue in small parcels. The parcels must be small enough to obtain adequate nutrition through plasmatic imbibition until such time as neovascularization of the fat parcels occurs. To accomplish this using a standard syringe device, the cannula (ie, syringe needle) is passed through the tissue multiple times, depositing a small amount of fat with each pass ${ }^{13}$ (Figure 1).

Currently, the principal method of injecting fat and other filler materials is to manually advance the plunger into the syringe as the cannula is withdrawn from the tissue. This seemingly simple procedure is subject to considerable human variability that directly impacts the final clinical appearance. Injected fat tends to be of an irregular consistency which causes variable resistance to depression of the plunger. Also, tissue resistance varies. This combination of factors increases the difficulty for the surgeon to inject a consistent thread of fat as the cannula is withdrawn. Thus, there is a tendency for the fat to be deposited in clumps, which may result in an irregular distribution into the recipient bed and subsequent necrosis at the center of the clumps (Figures 2 and 3). Furthermore, there is considerable intersurgeon variability in injection technique, further increasing the likelihood of inconsistent results.

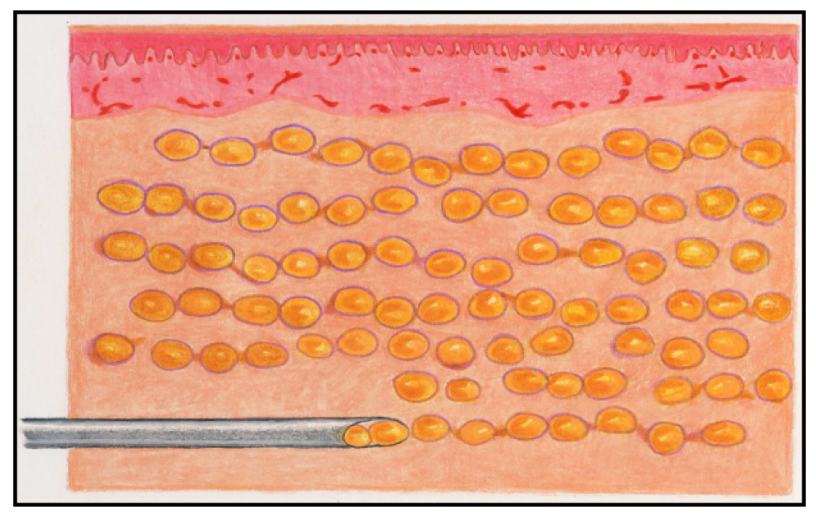

Figure I lllustration of evenly distributed fat parcels in the recipient tissue bed.

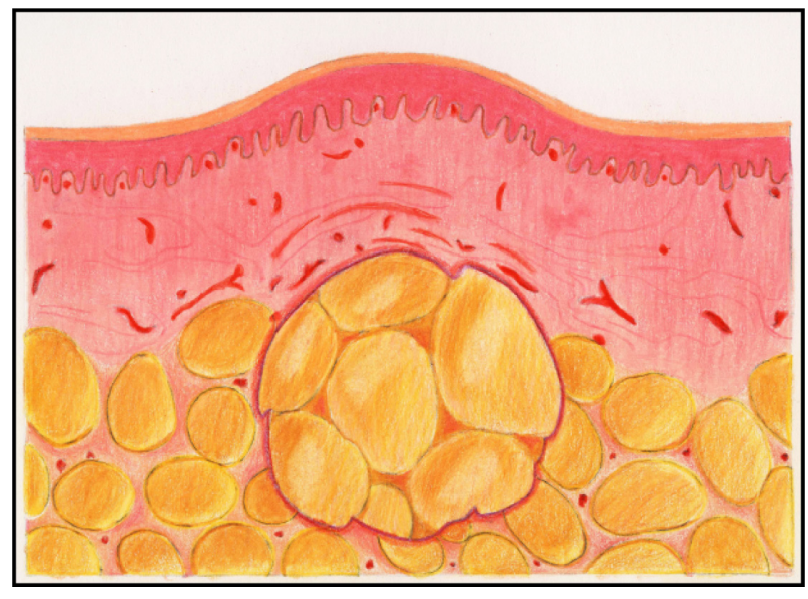

Figure 2 Illustration of fat distribution as a clump.

To maximize fat survival, it remains imperative to inject a consistent and reproducible volume of fat with each pass of the cannula. ${ }^{13}$ Placing too large of a volume with each pass will result in the death of a substantial portion of the fat cells and loss of volume. It will also result in inflammation, edema and irregular, unpredictable results. Placing an unnecessarily small volume of fat with each pass will result in excellent graft survival; however, the excessive number of cannula passes will contribute to prolonged postoperative edema. Furthermore, it is difficult to manually gauge the amount of fat injected with each pass of the cannula. The prolonged swelling and variable results discourage the use of facial fat grafting. The ideal technique will leave a consistent volume of fat with each pass of the cannula and thus yield consistent, predictable results and minimize tissue trauma.

In response to the challenge of injecting a consistent thread of fat with each pass of the cannula, a prototype injection control device (ICD) has been designed and manufactured. It mechanically deposits a fixed volume of filler material per unit distance that the cannula is withdrawn. This paper will present the initial experience using the ICD as an automated method to remove human error from the act of injecting as the cannula is withdrawn from the tissue.

\section{Materials and methods Device description}

The ICD consists of a patented gear system which precisely regulates the amount of filler material injected with each pass of the cannula (Figure 4). It consists of a syringe with a modified plunger, a syringe carrier, and a positioning guide.

The device utilizes a standard, commercially available $1 \mathrm{~mL}$ ( $1 \mathrm{cc}$ ) Luer-Lok ${ }^{\mathrm{TM}}$ disposable syringe (BARD, Murray Hill, NJ, USA). The plunger was replaced with one specially 


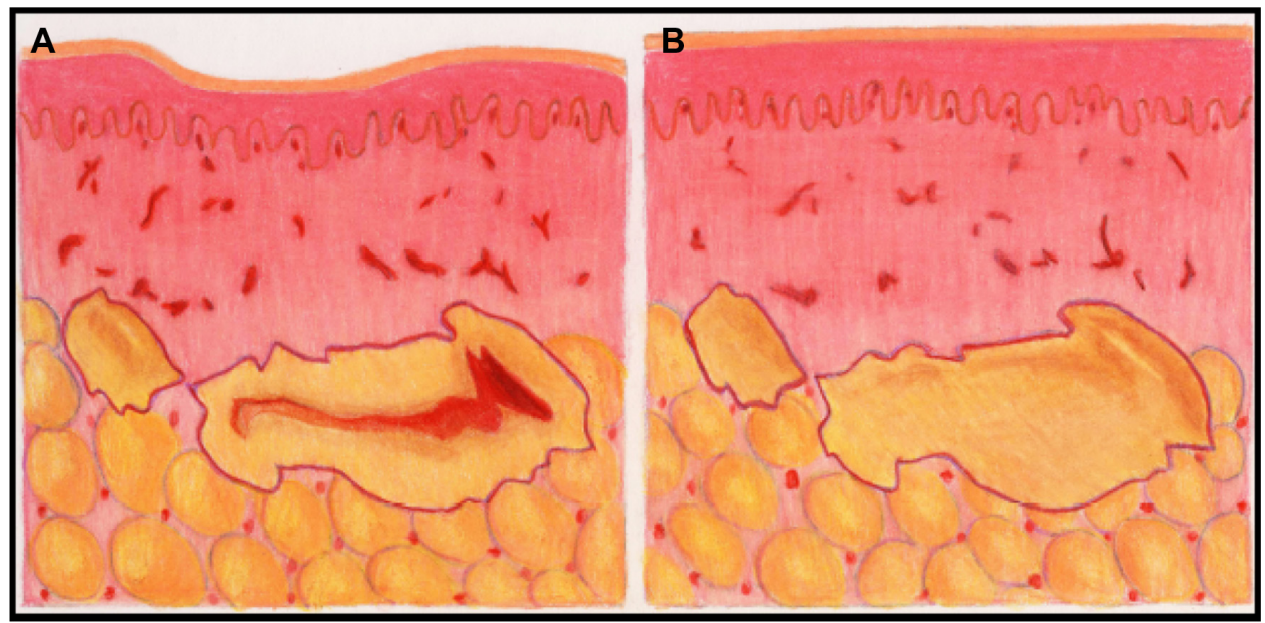

Figure 3 Illustration of tissue necrosis occurring when a large clump of fat is not amenable to neovascularization.

designed to work with the device. The plunger incorporates a gear rack which engages the reduction gear on the syringe cylinder carrier. Roller bearings on the syringe carrier hold the plunger rod against the reduction gear.

The syringe carrier or body of the device holds the cylinder securely. It has a reduction gear which contacts a rack on the positioning guide and the rack on the syringe plunger. The reduction gear incorporates a clutch mechanism which causes fat to be injected only when the cannula is withdrawn. The syringe plunger does not move relative to the syringe when the positioning guide is returned to the retracted position. The syringe carrier also incorporates a constant torque spring motor, which causes the positioning guide to retract automatically and holds it in the retracted position until the operator has reinserted the cannula and is ready to begin another injection stroke. The syringe carrier separates into two parts in order to insert the syringe and cannula.

The positioning guide consists of a rack with an attached thumb ring to allow the operator to hold it stationary with respect to the patient. The rack engages with the reduction gear on the syringe carrier. It is held stationary against the skin surface as the syringe carrier is withdrawn. It is then allowed to automatically retract into the syringe carrier before advancing the cannula into the tissue to repeat the cycle.

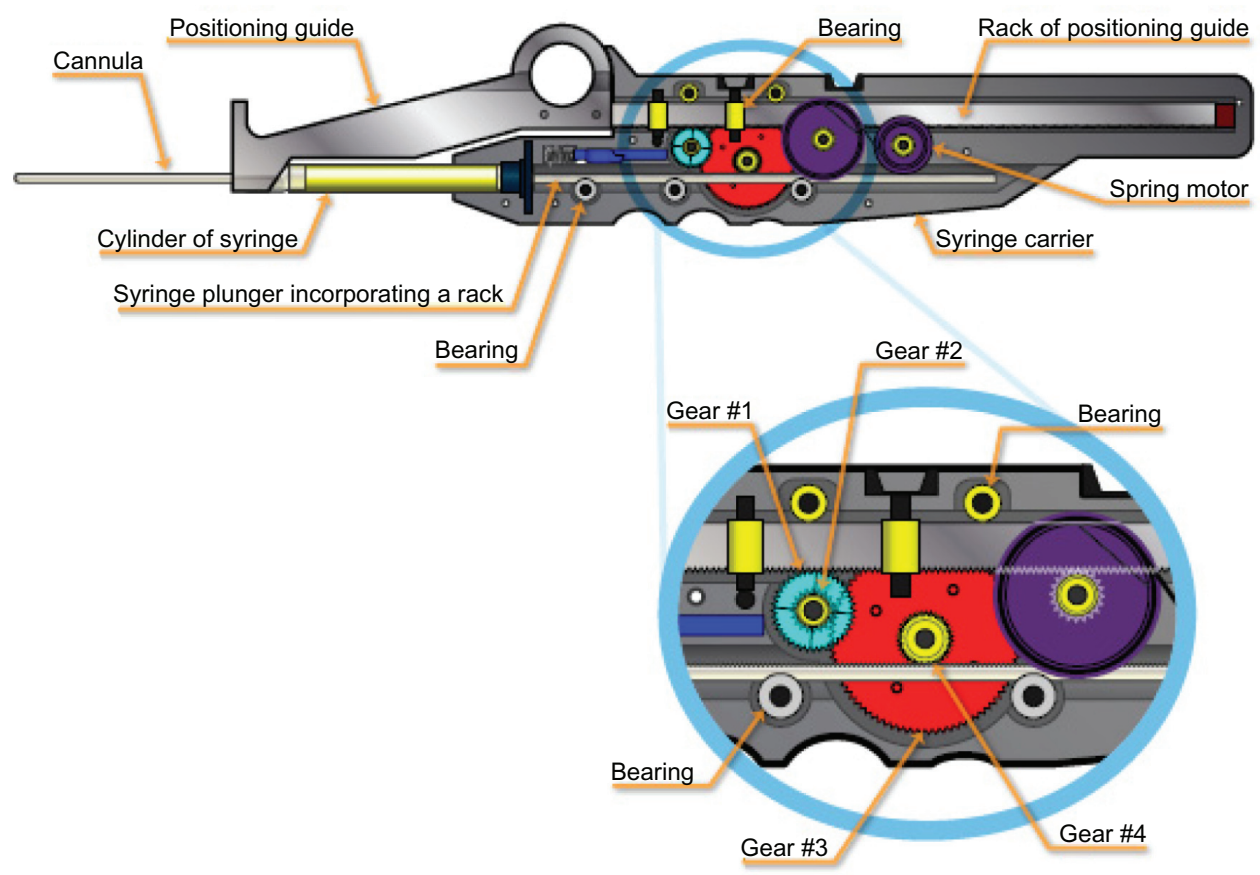

Figure 4 The injection control device (ICD). 
The gear ratio of the prototype version of the device is 5.209:1. For every $5.209 \mathrm{~cm}$ the syringe carrier is withdrawn relative to the positioning guide, the plunger is advanced $1 \mathrm{~cm}$ into the syringe. Given the commercially available $1 \mathrm{cc}$ syringe that the device is designed to use, the device will inject $33 \mathrm{uL}$ of filler material for every $1 \mathrm{~cm}$ the cannula is withdrawn from the tissue. This is slightly less than the internal volume of a 12-gauge cannula. The fat is uniformly distributed along the cannula tract, leaving consistent threads of fat in the recipient bed. In effect, the device replaces the surgeon's thumb with an automated gear mechanism to depress the plunger.

The cannula, syringe, and the device are advanced as a unit as the cannula is advanced into the tissue (Figure 5). The positioning guide is stabilized relative to the patient as the syringe carrier, syringe, and cannula are withdrawn. This causes the gear train to turn and advance the plunger into the syringe. The result is a consistent thread of fat that is the same volume, regardless of how fast the cannula is withdrawn. The positioning guide is then released, and the spring mechanism causes it to retract into the body of the syringe carrier. The cycle is then repeated. The key to the function of the device is the clutch mechanism, which allows the plunger to move only as the cannula is withdrawn from the tissue. The plunger remains stationary with respect to the syringe as the positioning guide automatically retracts.

The clutch contained within gear \#1 locks it to the axle as the cannula is withdrawn and causes the gear train to drive

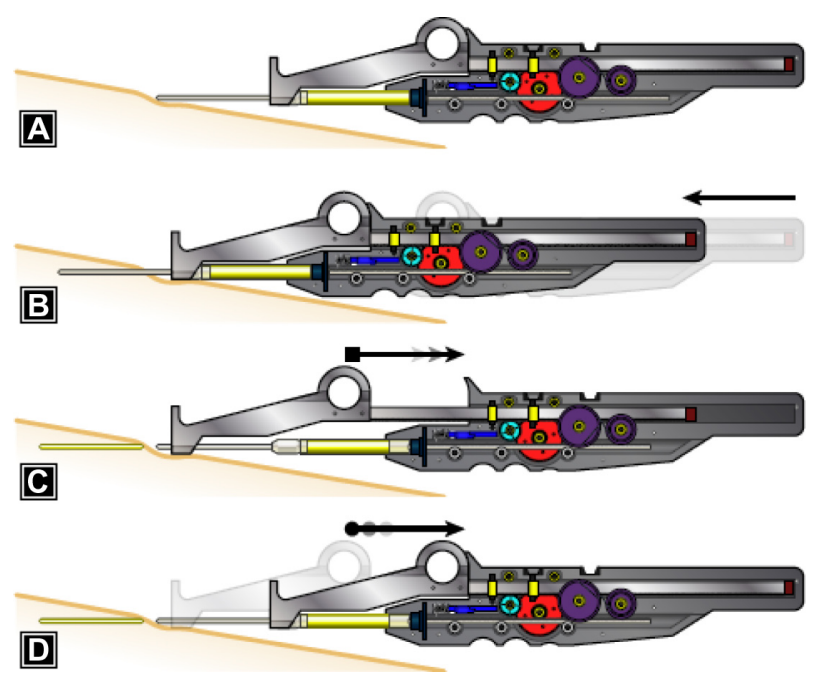

Figure 5 Injection control device (ICD) function.

Notes: (A) The device in the starting position. From this position, it is advanced as a unit, advancing the cannula into the tissue. (B) The cannula is inserted into the tissue. At this position, the positioning guide is secured stationary with respect to the patient's skin surface. (C) The syringe carrier containing the syringe and cannula are withdrawn as a unit, causing the gear train to drive the plunger into the syringe and deposit the fat in a uniform thread. (D) The positioning guide has been released, and the spring motor has caused it to automatically retract into the syringe carrier, returning to the starting position. The cannula is slightly redirected and advanced into the tissue to repeat the cycle. the plunger into the syringe. The clutch allows gear \#1 to rotate freely on its axle and not rotate the remainder of the gear train as the positioning guide is retracted back into the syringe carrier. There is a second clutch fixed to the syringe carrier case, which engages the second axle and allows gears \#2-4 to turn in only one direction. Thus, fat is injected only when the syringe carrier, syringe, and cannula are pulled away from the positioning guide.

This prototype device was designed by the primary author using computer-aided design software. The body of the device was constructed using computerized assisted manufacturing techniques. Most of the components were modified from commercially available stock drive parts.

\section{Fat harvest procedure}

Fat was harvested in the manner previously described by Coleman. ${ }^{14}$ Local tumescent anesthesia was used to anesthetize the donor sites. The fat was harvested using syringe liposuction with minimal negative pressure using $10 \mathrm{~mL}$ syringes. The fat was centrifuged for 3 minutes at 3,000 rpm. The saline layer was decanted, and the oil layer was wicked. The fat was then transferred into multiple $1 \mathrm{cc}$ syringes.

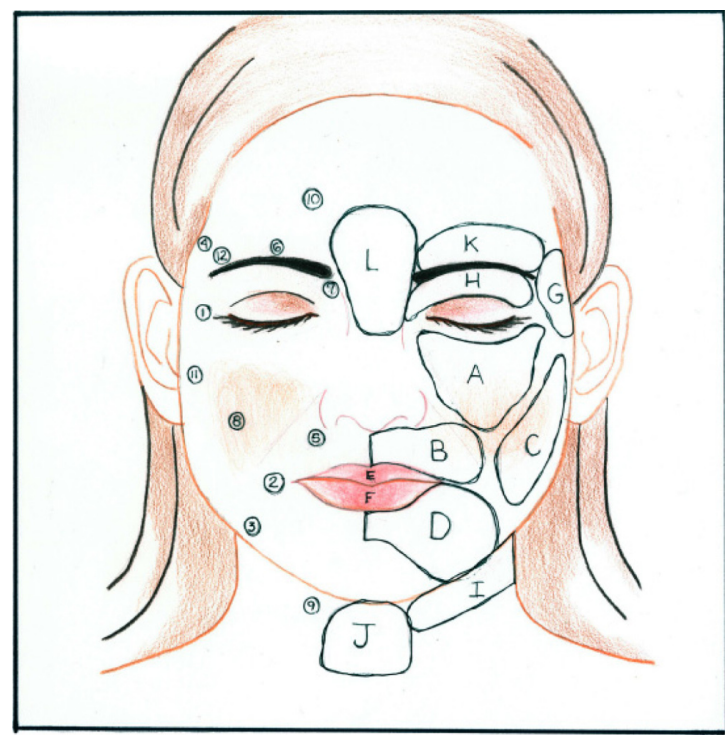

Figure 6 Drawing of face with zones and ports.

Notes: A, mid-facial region; B, upper lip extending superolaterally $5-10 \mathrm{~mm}$ beyond the melolabial fold; C, cheek; D, lower lip to the chin; E, vermillion of the upper lip; F, vermillion of the lower lip; G, hollow of the temple; H, superior eyelid; I, submandibular region; J, submental region; K, brow and supra-brow; L, glabella. I, located approximately I cm lateral and inferior to the lateral canthus; 2 , approximately $1 \mathrm{~cm}$ lateral to the oral commissure; 3 , located at the jaw line approximately $1.5 \mathrm{~cm}$ lateral to a line drawn vertically through the oral commissure; 4 , at the hairline, superior to the hollow of the temple; 5 , junction of the alar lobule and the melolabial fold; 6, in the eyebrow, superior to the pupil; 7 , in the eyebrow, superior to the medial canthus; 8 , in the lateral portion of the malar mound, lateral to the end of the tear through crease; 9 , lateral submentum of the jawline; 10, $2 \mathrm{~cm}$ superior to the brow in the mid-pupillary line; $1 \mathrm{I}, \mathrm{I} \mathrm{cm}$ anterior to the tragus; 12, directly superior to the lateral canthus at the brow line. 


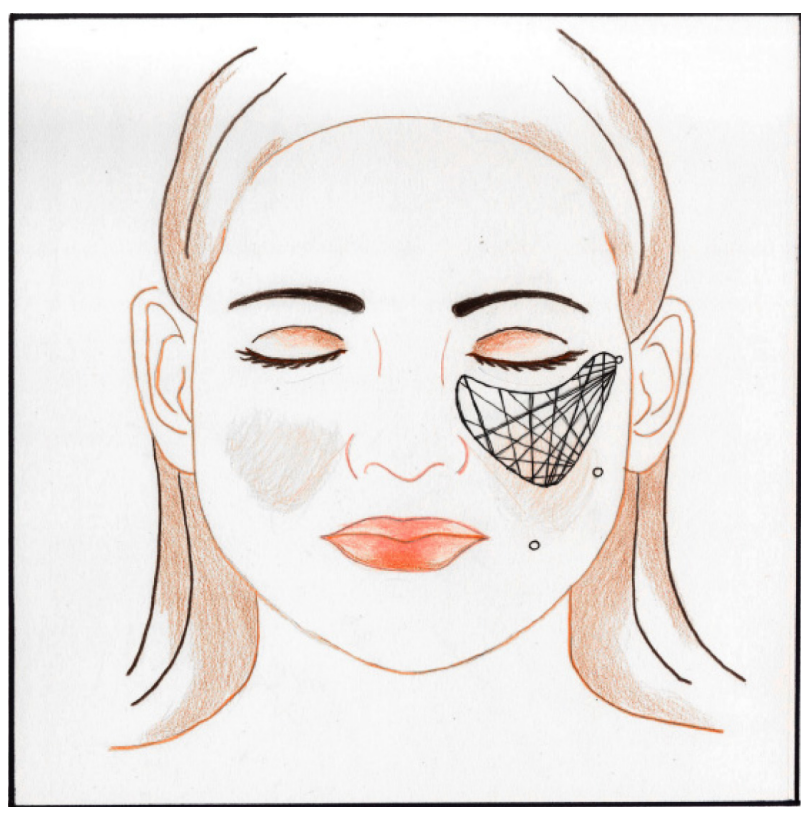

Figure 7 Drawing of face demonstrating crosshatch pattern.

\section{Operative technique}

Local anesthetic was infiltrated into the areas to be augmented using a blunt cannula to minimize the chance of hematoma. The face was divided into zones, which were arbitrarily designated by letters (Figure 6). The injection ports were designated by numbers. Eighteen-gauge Coleman ${ }^{\circledR}$ (Mentor, Santa Barbara, CA, USA) type 1 cannulas were used to inject the fat. Each zone was injected through more than one port (Figure 7). This resulted in a crosshatch pattern of fat threads. The fat was injected into the deeper muscle layers. The exception was along the vermillion border where the fat was injected more superficially. No dressings were applied unless needed for procedures performed concomitantly. The patients were instructed to intermittently apply cold gel packs to the treated areas for the first 24 hours after surgery. Postoperative medications included cephalexin $500 \mathrm{mg}$ three times a day (TID) for 10 days, acetaminophen/oxycodone, and a short burst and taper of prednisone. Patients also were

Table I List of patients, zones grafted, and associated procedures

\begin{tabular}{|c|c|c|c|c|c|}
\hline Patient \# & Age & Zones grafted* & Total amount grafted (ccs) & Associated procedures & Procedure $^{\#}$ \\
\hline 1 & 56 & A,B,C,D,E,F,G & 36 & Facelift & I \\
\hline 2 & 54 & $A, B, C, D, E$ & 34 & Facelift, mentoplasty & I \\
\hline 3 & 54 & $\mathrm{~A}, \mathrm{~B}, \mathrm{C}, \mathrm{D}, \mathrm{E}, \mathrm{F}$ & 26 & Facelift & I \\
\hline 4 & 61 & $A, B, C, D, E, F$ & 36 & Facelift, cervicofacial liposuction & I \\
\hline I & 56 & $A, B, C, D, E, F$ & 28 & $\begin{array}{l}\text { Endo brow, upper blepharoplasty, SurgiWire } \\
\text { melolabial folds, cervical rhytids }\end{array}$ & 2 \\
\hline 5 & 55 & $A, B, D, E, F$ & 24 & Facelift & I \\
\hline 6 & 51 & $A, B, C, D, E, F, G$ & 40 & Facelift & I \\
\hline 7 & 49 & $A, B, C, D, E, F, G$ & 42 & & I \\
\hline 8 & 45 & A,B,C,D,E,F,I,J & 50 & Brow lift & I \\
\hline 9 & 46 & $A, B, C, D, E, F, G, H$ & 52 & & I \\
\hline 10 & 43 & $\mathrm{~A}, \mathrm{~B}, \mathrm{C}, \mathrm{D}, \mathrm{E}, \mathrm{F}, \mathrm{G}, \mathrm{H}, \mathrm{K}, \mathrm{L}$ & 76 & & I \\
\hline 11 & 54 & $A, B, C, D, E, F, G, K, M$ & 69 & & I \\
\hline 12 & 43 & $B, D, E$ & 24 & & I \\
\hline 13 & 62 & $\mathrm{~A}, \mathrm{~B}, \mathrm{C}, \mathrm{D}, \mathrm{E}, \mathrm{F}, \mathrm{G}, \mathrm{H}, \mathrm{I}, \mathrm{K}, \mathrm{L}$ & 80 & & I \\
\hline I & 57 & $A, D, E, F, G$ & 34 & Rhinoplasty & 3 \\
\hline 14 & 38 & $A, B, D, E, F, G$ & 24 & & I \\
\hline 15 & 44 & $\mathrm{~A}, \mathrm{~B}, \mathrm{C}, \mathrm{D}, \mathrm{E}, \mathrm{F}, \mathrm{G}, \mathrm{H}, \mathrm{K}, \mathrm{L}$ & 63 & & I \\
\hline 16 & 52 & A,B,D,E,F,G,H,K,L & 49 & Rhinoplasty, chin implant & I \\
\hline 17 & 51 & $\mathrm{~A}, \mathrm{~B}, \mathrm{C}, \mathrm{D}, \mathrm{E}, \mathrm{F}, \mathrm{G}, \mathrm{H}, \mathrm{K}, \mathrm{L}$ & 92 & & I \\
\hline 18 & 50 & $\mathrm{~A}, \mathrm{~B}, \mathrm{D}, \mathrm{E}, \mathrm{F}, \mathrm{G}, \mathrm{H}, \mathrm{K}, \mathrm{L}$ & 61 & & I \\
\hline 19 & 60 & $\mathrm{~A}, \mathrm{~B}, \mathrm{D}, \mathrm{E}, \mathrm{F}, \mathrm{K}, \mathrm{L}$ & 55 & Facelift & I \\
\hline 20 & 63 & $\mathrm{~A}, \mathrm{~B}, \mathrm{C}, \mathrm{D}, \mathrm{E}, \mathrm{F}, \mathrm{G}, \mathrm{H}, \mathrm{I}, \mathrm{K}, \mathrm{L}$ & 112 & Otoplasty & I \\
\hline 21 & 57 & A,B,D,E,F,G,H,K,L & 98 & & I \\
\hline 22 & 48 & $\mathrm{~A}, \mathrm{~B}, \mathrm{C}, \mathrm{D}, \mathrm{E}, \mathrm{F}, \mathrm{G}, \mathrm{H}, \mathrm{K}, \mathrm{L}$ & 110 & & I \\
\hline 23 & 44 & $\mathrm{~A}, \mathrm{~B}, \mathrm{D}, \mathrm{E}, \mathrm{F}, \mathrm{G}, \mathrm{H}, \mathrm{K}, \mathrm{L}$ & 96 & & I \\
\hline 7 & 51 & $\mathrm{~A}, \mathrm{~B}, \mathrm{D}, \mathrm{E}, \mathrm{F}, \mathrm{G}, \mathrm{H}, \mathrm{K}$ & 59 & & 2 \\
\hline 24 & 43 & $\mathrm{~A}, \mathrm{~B}, \mathrm{D}, \mathrm{E}, \mathrm{F}, \mathrm{G}, \mathrm{H}, \mathrm{K}, \mathrm{L}$ & 82 & & I \\
\hline 25 & 52 & $A, B, D, E, F, G$ & 82 & $\begin{array}{l}\text { Facelift, upper blepharoplasty, } \\
\text { cervical liposuction }\end{array}$ & I \\
\hline 10 & 45 & A & 3 & Microliposuction (revision) & 2 \\
\hline 26 & 45 & $A, B, C, D, E, F, G, K, L$ & 94 & & I \\
\hline
\end{tabular}

Notes: *Zones grafted (A-L) are detailed in Figure 6, "Number of procedures administered per patient. 
instructed to sleep with the head of the bed elevated for six weeks after the procedure.

Operation of the device requires the surgeon to stabilize the tissue with the nondominant hand while the cannula is advanced into the tissue with the dominant hand. The nondominant hand is then used to stabilize both the tissue and the positioning guide as the device and cannula are withdrawn.

\section{Patients}

The experimental nature of the device was explained to the patients in this study and informed consent was obtained both orally and in writing.

In this series, a total of 26 patients underwent 30 facial fat-grafting procedures using this device with a minimum of four months follow-up (Table 1). Thirteen of the fat-grafting cases were done in conjunction with other facial aesthetic surgical procedures. Seventeen cases were done without associated rejuvenation procedures. Two patients underwent a single subsequent fat-grafting procedure and one underwent

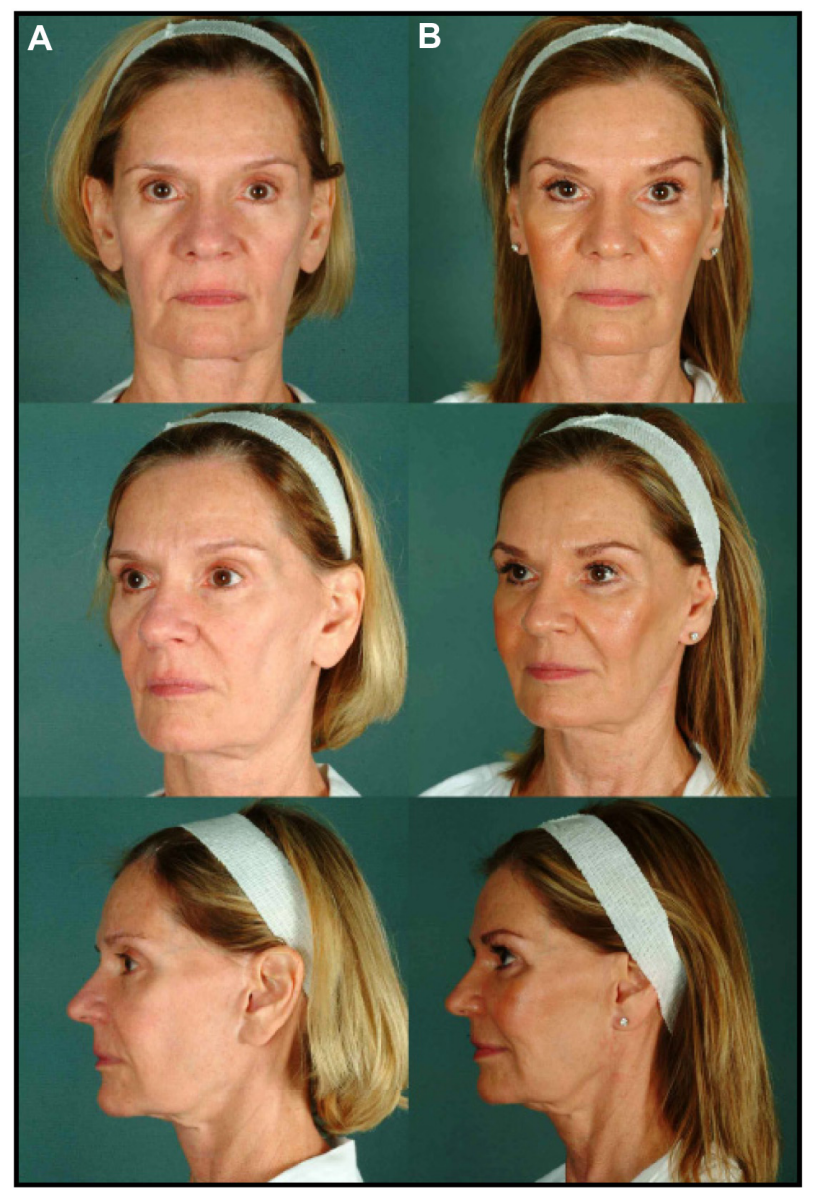

Figure 8 Before $(\mathbf{A})$ and I-year postop (B).

Note: This 63-year-old patient had II2 cc fat grafted to the midface, cheeks, lips, upper eyelids, temples, brows, forehead, and neck. two. One of the patients undergoing the second procedure and the patient who underwent the two subsequent facial fatgrafting procedures were operated on early in the series and were initially treated more conservatively. The other patient undergoing the second procedure required a minor amount of touch-up, along with microliposuction, to correct a slight overcorrection of the infraorbital region.

Preoperative photographs were compared with photographs obtained four or more months postoperatively. Additionally, photographs were obtained which document the immediate postoperative course.

\section{Results}

Patients reported minimal discomfort after the procedure, requiring little or no analgesia.

The results were subjectively compared with the author's prior experience with facial fat grafting, using the conventional technique of manually advancing the plunger of a standard syringe as the cannula is withdrawn. Figures 8-11 illustrate

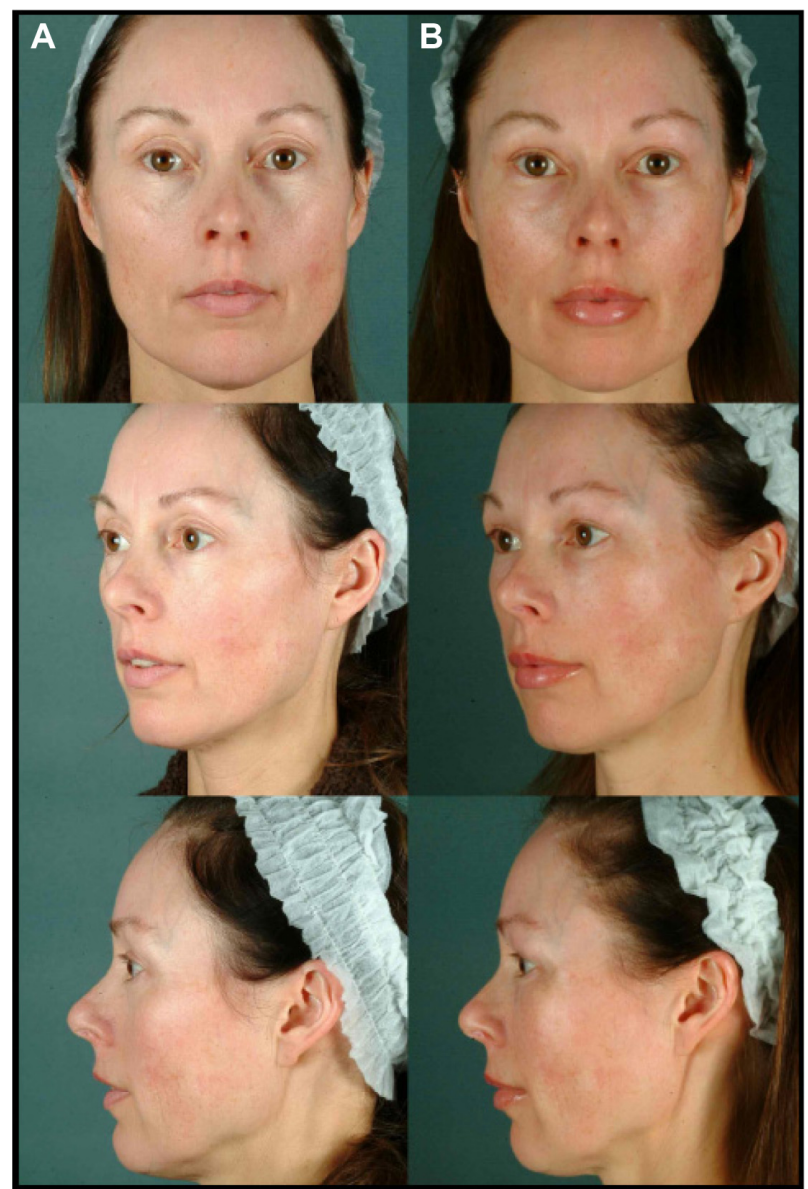

Figure 9 Before (A) and 4-month postop (B).

Note: This 43-year-old patient had $76 \mathrm{cc}$ fat grafted to the midface, cheeks, lips, upper eyelids, temples, brows, and forehead. 


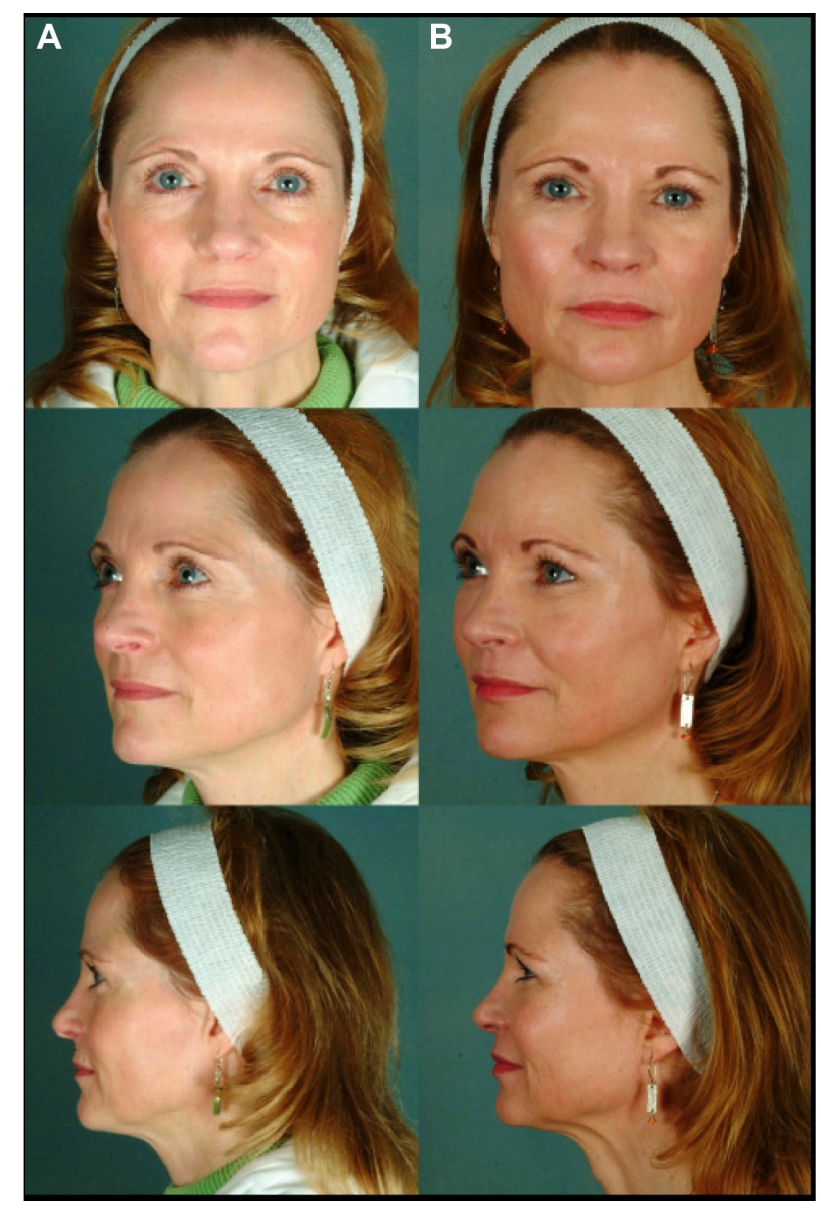

Figure 10 Before (A) and 6-month postop (B).

Note: This 48-year-old patient had 110 cc fat grafted to the midface, cheeks, lips, upper eyelids, temples, brows, and forehead. typical results. More consistent clinically aesthetic results were observed with the ICD, as well as faster recovery, and reduced operating time when compared to the manual method.

Few minor complications were encountered. In two cases, there were palpable threads along the infraorbital rim, which were not visible. In two cases, there was a minor degree of irregularity in the infraorbital region which persisted at six months postop and was easily corrected with microliposuction of the area. These complications occurred in patients with thin skin and thin subcutaneous tissue. This suggests that a modification of the ICD that produces a lower "injection ratio" may be more appropriate in the periorbital region.

\section{Discussion}

It is hypothesized that human error, associated with coordinating the depression of the plunger with the withdrawal of the cannula, is a principal source of the variability of fatgrafting results. Mechanically linking the depression of the plunger to the withdrawal of the cannula may yield results that are more consistent, predictable, and less traumatic. Less tissue trauma may, in turn, result in less postoperative edema and bruising and a faster recovery.

The technique of depressing a syringe plunger as the cannula is withdrawn from the tissue is associated with potentially multiple sources of human error. Fat prepared for injection has an irregular consistency and tissue resistance varies. Both of these factors lead to variable resistance

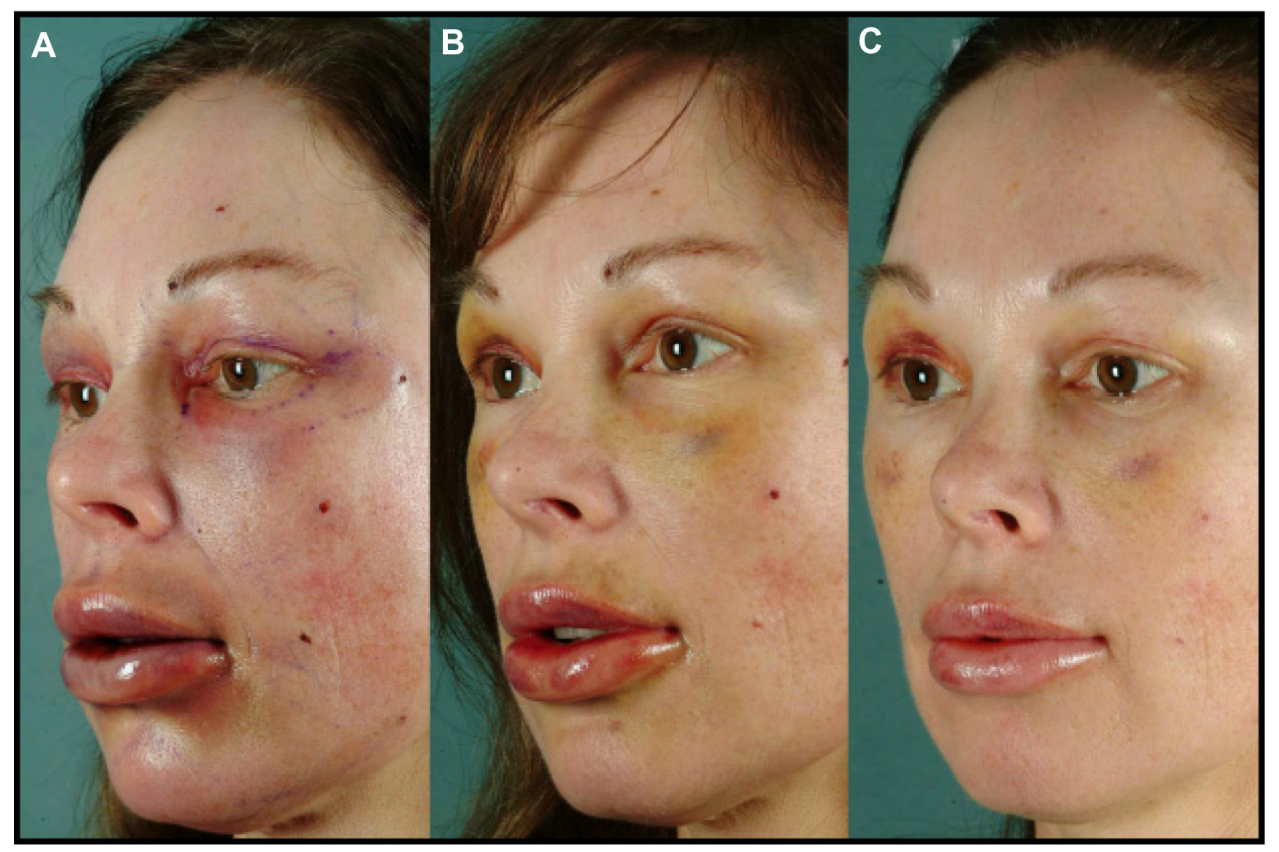

Figure I I Sequential early postop photos at postoperative days I (A), 7 (B), and I 4 (C). 
to depressing the plunger, which can cause inconsistent flow from the cannula. Also, each individual surgeon has a different interpretation of the injection technique. All of these factors contribute to the wide range of clinical results observed in published studies and to the long learning curve associated with this procedure.

The ICD distributes uniform threads of fat in the recipient tissue bed, regardless of the consistency of the fat or how fast the cannula is withdrawn from the tissue. Variable resistance is irrelevant because the device provides the surgeon with a greater than 5:1 mechanical advantage in depressing the plunger. Thus, clumping is eliminated. The clinical results are much more consistent and subsequent aesthetic appearance far more satisfactory. Moreover, the elimination of clumping results in less graft necrosis. This contributes to the consistency and predictability of the result and hastens the resolution of the inflammatory response.

The device minimizes unnecessary tissue trauma. Since a consistent amount of fat is injected each time, there are no "empty passes" of the cannula in which a suboptimal amount of fat is injected. This allows the surgeon to focus on the location and amount of fat to be injected instead of operative technique, making fat grafting more efficient and reducing operative time.

Invariably, no two surgeons will manually inject fat in exactly the same ratio. This is one likely source of the long learning curve as each surgeon learns what to expect from his or her own individual technique. Use of this device standardizes the procedure and should make it easier to teach and learn.

Potential design improvements of this prototype became evident during the series. The device is significantly larger than the syringe it contains. It is reusable, which represents a significant capital cost. The present design uses a 1 cc syringe, and repeated changes are time consuming. A miniaturized, single-use, disposable version - modified to accommodate a larger syringe - will correct these deficiencies.

The optimal amount of fat injected per unit distance that the cannula is withdrawn (injection ratio) is not known. It likely varies by application of the technique. Areas of thin coverage, such as the periorbital area, are likely treated with a lower injection ratio, compared to areas of thicker coverage, like the cheek. Corporeal fat augmentation to areas, such as the breast or buttocks, can likely be treated most optimally with a higher injection ratio.

One limitation of this feasibility study was the lack of a comparative control group using the standard manual syringe technique to inject fat. Although beyond the scope of the current investigation, this would be most efficiently evaluated using a split-face model with quantitative camera imaging to assess degree and maintenance of correction.

\section{Conclusion}

The ICD greatly facilitates fat grafting by injection. It replaces the human thumb in depressing the plunger of the syringe as the cannula is withdrawn from the tissue. This automation removes a potentially significant source of human error from this procedure. The results are consistently reproducible. The recovery is faster, and the procedure is more efficient.

\section{Acknowledgment}

All patients provided informed consent for using patient photos in this article.

\section{Disclosure}

Hetherington and Block are shareholders in Injection Technologies Inc, (San Francisco, CA, USA), which supported the development of this manuscript but did not provide funding for the conduct of the study. The authors report no other conflicts of interest in this work.

\section{References}

1. Neuber F. Fettransplantation NF. Chir Kongr Verhandl Dtsch Ges Chir. 1893: 22-66. Available from: http://www.histplastsurg.com/assets/files/ Hist $\% 20$ Plast $\% 20$ Surg\%202010\%20Vol1\%20Issue1\%20Pages 7-11. pdf. http://histplastsurg.com/index.php?id=57. Accessed July 20, 2013.

2. Illouz YG. The fat cell "graft": a new technique to fill depressions. Plast Reconstr Surg. 1986;78(1):122-123.

3. Johnson GW. Body contouring by macroinjection of autologous fat. American Journal of Cosmetic Surgery. 1987;4(2):103-109.

4. Krulig E. Lipo-injection. American Journal of Cosmetic Surgery. 1987;4(2):123-129.

5. Newman J, Levin J. Facial lipo-transplant surgery. American Journal of Cosmetic Surgery. 1987;4(2):131-140.

6. Coleman SR. Long-term survival of fat transplants: controlled demonstrations. Aesthetic Plast Surg. 1995;19(5):421-425.

7. Ersek RA. Transplantation of purified autologous fat: a 3-year follow-up is disappointing. Plast Reconstr Surg. 1991;87(2):219-227.

8. Fournier PF. Fat grafting: my technique. Dermatol Surg. 2000;26(12): $1117-1128$.

9. Fulton JE, Suarez M, Silverton K, Barnes T. Small volume fat transfer. Dermatol Surg. 1998;24(8):857-865.

10. Hörl HW, Feller AM, Biemer E. Technique for liposuction fat reimplantation and long-term volume evaluation by magnetic resonance imaging. Ann Plast Surg. 1991;26(3):248-258.

11. Goldman R, Carmargo CP, Goldman B. Fat transplantation and facial contour. American Journal of Cosmetic Surgery. 1998;15(1):41-44.

12. Thanik VD, Chang CC, Lerman OZ, et al. A murine model for studying diffusely injected human fat. Plast Reconstr Surg. 2009;124(1): 74-81.

13. Meier JD, Glasgold RA, Glasgold MJ. Autologous fat grafting: long-term evidence of its efficacy in midfacial rejuvenation. Arch Facial Plast Surg. 2009;11(1):24-28.

14. Coleman SR. Structural fat grafts: the ideal filler? Clin Plast Surg. 2001; 28(1):111-119. 


\section{Publish your work in this journal}

Clinical, Cosmetic and Investigational Dermatology is an international, peer-reviewed, open access, online journal that focuses on the latest clinical and experimental research in all aspects of skin disease and cosmetic interventions. All areas of dermatology will be covered; contributions will be welcomed from all clinicians and basic science researchers globally. This journal is indexed on CAS. The manuscript management system is completely online and includes a very quick and fair peer-review system, which is all easy to use. Visit http://www.dovepress.com/testimonials.php to read real quotes from published authors.

Submit your manuscript here: http://www.dovepress.com/clinical-cosmetic-and-investigational-dermatology-journal 